\title{
Correction to: Biosolids application affects the competitive sorption and lability of cadmium, copper, nickel, lead, and zinc in fluvial and calcareous soils
}

\author{
Sabry M. Shaheen • Vasileios Antoniadis • Eilhann E. Kwon · Jayanta K. Biswas • \\ Hailong Wang · Yong Sik Ok · Jörg Rinklebe
}

Published online: 4 January 2018

(C) Springer Science+Business Media B.V., part of Springer Nature 2017

\section{Correction to: Environ Geochem Health \\ (2017) 39:1365-1379 \\ https://doi.org/10.1007/s10653-017-9927-4}

Unfortunately, in the original publication of the article, Prof. Yong Sik Ok's affiliation was incorrectly published. The author's affiliation is as follows.
1. Kangwon National University, Chuncheon 24341, Republic of Korea

2. O-Jeong Eco-Resilience Institute (OJERI), Division of Environmental Science and Ecological Engineering, Korea University, Seoul, Republic of Korea
The original article can be found online at https://doi.org/10.1007/s10653-017-9927-4.

S. M. Shaheen $(\bowtie)$

Department of Soil and Water Sciences, Faculty of Agriculture, University of Kafrelsheikh,

33516 Kafr El-Sheikh, Egypt

e-mail: smshaheen@agr.kfs.edu.eg

\section{S. M. Shaheen · J. Rinklebe}

School of Architecture and Civil Engineering, Institute of Foundation Engineering, Water- and Waste-Management, Soil- and Groundwater-Management, University of Wuppertal, Pauluskirchstraße 7, 42285 Wuppertal, Germany

e-mail: rinklebe@uni-wuppertal.de

V. Antoniadis

School of Agriculture, University of Thessaly, Fytokou Street, 38446 Volos, Greece

e-mail: vasilisrev@yahoo.com
E. E. Kwon · J. Rinklebe

Department of Environment and Energy, Sejong

University, Seoul 05006, Korea

e-mail: ekwon74@sejong.ac.kr

J. K. Biswas

Department of Ecological Engineering and Environmental Management, University of Kalyani, Nadia,

West Bengal 741235, India

e-mail: biswajoy2000@yahoo.com

H. Wang

Key Laboratory of Soil Contamination Bioremediation of Zhejiang Province, School of Environmental and Resource Sciences, Zhejiang A \& F University, Lin'an, Hangzhou 311300, Zhejiang Province, China e-mail: nzhailongwang@gmail.com; nzhailongwang@163.com 
H. Wang

School of Environmental and Chemical Engineering,

Foshan University, Foshan 528000, Guangdong, China

Y. S. Ok

School of Natural Resources and Environmental Science and Korea Biochar Research Center, Kangwon National University, Chuncheon 24341, Korea

e-mail: soilok@kangwon.ac.kr

Y. S. Ok

O-Jeong Eco-Resilience Institute (OJERI), Division of Environmental Science and Ecological Engineering,

Korea University, Seoul, Republic of Korea

e-mail: yongsikok@korea.ac.kr

\section{Springer}

